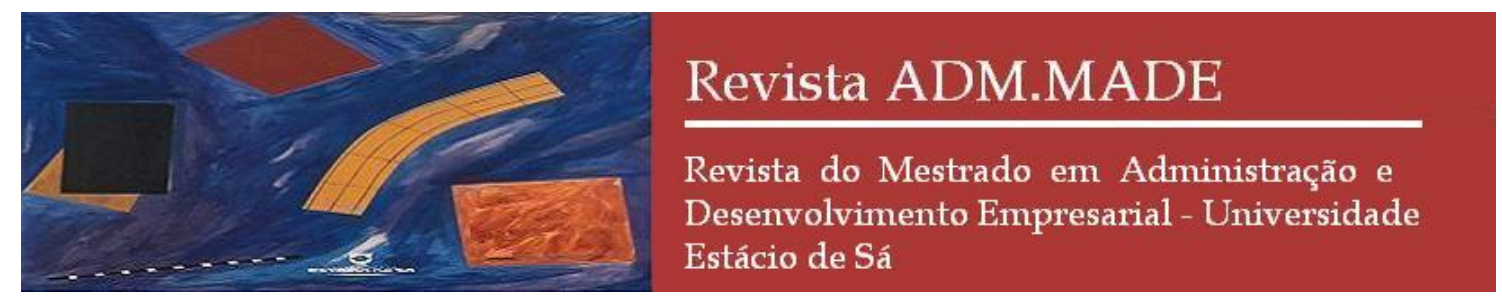

Revista ADM.MADE, Rio de Janeiro, ano 16, v.20, n.3, p.43-61, setembro/dezembro, 2016 http://dx.doi.org/10.21714/2237-51392016v20n3p043061

Revista do Mestrado em Administração e Desenvolvimento Empresarial da Universidade

Estácio de Sá - Rio de Janeiro (MADE/UNESA). ISSN: 2237-5139

Conteúdo publicado de acesso livre e irrestrito, sob licença Creative Commons 3.0. Editor responsável: Cecília Lima de Queirós Mattoso

\title{
Cultura Material e Materialismo: Explorando os Valores, os Significados, as Características e as Influências no Consumo de Joias
}

\author{
Paula Karina Salume 1 \\ Marcelo de Rezende Pinto ${ }^{2}$ \\ Liliane de Oliveira Guimarães ${ }^{3}$
}

\footnotetext{
Artigo recebido em 01/06/2015 e aprovado em 20/04/2017. Artigo avaliado em double blind review.

${ }^{1}$ Doutora em Administração pela Pontifícia Universidade Católica de Minas Gerais. Professora do Departamento de Administração da Pontifícia Universidade Católica de Minas Gerais - PUC Minas. Endereço: Av. Itaú 525 Prédio Redentoristas-Bairro Dom Cabral. CEP: 30535-012 - Belo Horizonte, MG. E-mail: paulasalume@hotmail.com.

${ }^{2}$ Doutor em Administração pela Universidade Federal de Minas Gerais. Professor do Programa de Pós-graduação em Administração da Pontifícia Universidade Católica de Minas Gerais (PPGA PUC Minas). Endereço: Av. Itaú 525 - Prédio Redentoristas - Bairro Dom Cabral. CEP: 30535-012 - Belo Horizonte, MG. E-mail: marcrez@hotmail.com. ${ }^{3}$ Doutora em Administração pela Escola de Administração de Empresas da Fundação Getúlio Vargas de São Paulo (EAESP/FGV/SP). Professora do Programa de Pós-graduação em Administração da Pontifícia Universidade Católica de Minas Gerais (PPGA PUC Minas). Endereço: Av. Itaú 525 - Prédio Redentoristas - Bairro Dom Cabral. CEP: 30535-012 - Belo Horizonte, MG. E-mail: lilianeog@pucminas.br.
} 


\section{Cultura Material e Materialismo: Explorando os Valores, os Significados, as Características e as Influências no Consumo de Joias}

O artigo apresenta e discute resultados de uma pesquisa empírica, realizada por meio de survey on line, que investiga a relação entre materialismo e outros aspectos importantes no consumo de joias junto a amostra de consumidores. Na revisão da literatura, priorizaram-se discussões atinentes à questão da cultura material e aos pontos considerados relevantes no consumo de joias. Os dados obtidos de 216 questionários válidos foram analisados por meio de técnicas estatísticas como análise de regressão e análise de cluster. Os resultados sinalizaram que existem evidências estatísticas quanto à relação entre o construto materialismo e os construtos valor, significados, características e influências no consumo de joias, o que parece estar de acordo com a literatura relacionada à cultura material.

Palavras-chave: Consumo de Joias; Cultura Material; Valor Percebido; Significados.

Keywords: Consumption of Jewelry; Material Culture; Perceived value; Meanings.

\section{Material Culture and Materialism: Exploring Values, Meanings, the Features and Influences Consumption of Jewelry}

This paper presents and discusses results from an empirical study with a sample of consumers whose aim was to investigate the relationship between materialism and other important aspects of jewelry consumption. In the literature review, question of material culture and relevant points in the jewelry consumption were prioritized. An online survey was implemented to achieve the results. There was a return of 216 valid questionnaires. Data were analyzed using statistical techniques such as regression analysis, cluster analysis and test $t$. The results showed that there is statistical evidence regarding the relationship between materialism construct and the constructs value, meanings, characteristics and influences the consumption of jewelry, which seems to be in agreement with the literature related to material culture.

\section{INTRODUÇÃO}

Nos trabalhos envolvendo os estudos de consumo, é lugar comum a noção de que consumir pode ser considerado um dos fenômenos mais importantes das sociedades modernas (MCCRACKEN, 2003; BARBOSA, 2006; DESJEUX, 2011). Porém, o que ainda gera algum sentimento de estranheza é o fato de o consumo de massa ter sido considerado mais como um mal do que como um bem (ROCHA, 2002; MILLER, 2007).

Muito dessa tendência está relacionada ao sentido da palavra consumo, que, não raramente, é associada à derivação do latim consumere, que significa "usar tudo", "esgotar" e "destruir" (BARBOSA; CAMPBELL, 2006). Os debates morais atinentes ao consumo se juntam às críticas ambientalistas recentes, cujo viés semântico é novamente sinônimo de destruição (MILLER, 2007). Ou seja, a posse de bens tornou-se alvo de críticas pelo fato de ser considerado o vilão da sociedade contemporânea (McCRACKEN, 2012).

Contudo, parece haver uma contradição nessa interpretação do papel dos bens na vida comum dos indivíduos na moderna sociedade. O consumo é algo ativo e constante na vida diária, e nela desempenha papel central como estruturador de valores que constroem identidades, que regulam relações sociais, que definem mapas culturais, e assim por diante. 
Assim sendo, os bens são investidos de valores criados socialmente tanto para expressar categorias e princípios, quanto para cultivar ideias, para fixar e sustentar estilos de vida, ou para enfrentar mudanças (DOUGLAS; ISHERWOOD, 2006).

Os consumidores consideram seus pertences como parte deles, com os objetos constituindo uma extensão do self de cada pessoa (BELK, 1988). Os bens não somente são um reflexo de distinções de classe, mas essencialmente um meio de reprodução dessas distinções (BOURDIEU, 2007). Em suma, os bens parecem ser "instrumentos" que ajudam as pessoas a fazer escolhas, a tornar a cultura concreta e pública, e a selecionar, a assumir e a expor novos significados, entre outros. Ou seja, os bens auxiliam a aprender, a fazer, a expor e a mudar as preferências demandadas por uma sociedade individualista.

O que pode se destacar nessa discussão é a constatação de que existe uma noção arraigada de que os indivíduos puros, ou as relações sociais puras, são contaminados pela cultura dos bens (MILLER, 2007), trazendo à tona um conceito amplamente difundido que é o do materialismo. Ainda que o termo possa representar, de novo, um viés moralista do consumo, um apego ou uma devoção a objetos que tomam o lugar de um apego e de uma devoção a pessoas, existe um corpo de pesquisas considerável que busca entender o papel dos bens na vida dos indivíduos.

Na década de 1970, Justice e Birkman (1972) conduziram pesquisa tentando associar materialismo com traços de personalidade. Na mesma época, o estudo de Burdsal (1975), ao analisar fatores motivacionais e traços de personalidade, chegou a propor variáveis para se mensurar o grau de materialismo. Contudo, o conceito somente chegou ao campo do comportamento do consumidor nos anos 1980 com a publicação dos estudos de Belk (1984, 1985), que defende que o materialismo pode ser entendido como um traço de personalidade associado a três características que poderiam ser mensuradas no consumidor: possessividade, falta de generosidade e inveja.

Outros trabalhos relevantes foram publicados anos mais tarde, já na década de 1990, como os de Richins e Dawson (1992) e de Richins (1994). Os primeiros advogam que o materialismo deve ser entendido em uma perspectiva cultural, podendo ser desmembrado em três dimensões: centralidade, felicidade e sucesso.

Mais recentemente diversos estudos empíricos têm sido conduzidos tanto na Europa como nos Estados Unidos (GER; BELK, 1996; WATSON, 2003; GRIFFIN; BABIN; CHRISTENSEN, 2004) e diversas relações com outros construtos vêm sendo testadas empiricamente, a fim de se entender melhor o materialismo.

É justamente nesse contexto, marcado por polêmicas, por ambiguidades e por contradições, que se oportuniza a emergência de discussões sobre o consumo dos bens ditos caros, que, quase sempre, remetem ao conceito de materialismo - sobretudo produtos de luxo e, mais precisamente, o consumo de joias. Isso se dá face às características dos bens de luxo que, aderentes ao mercado de joias, levam à constatação de que, muito mais do que por sua função utilitária - ou seja, por aquilo que são - são valorizados, procurados e desejados por características mais subjetivas e intangíveis, sejam elas estimuladas por valores individuais ou culturais: aquilo que representam (SCARABOTO et al, 2006). 
Essas discussões parecem levar a alguns questionamentos que ainda não passaram por um devido escrutínio pelos pesquisadores do consumo: há relação entre consumo de joias e materialismo? Qual a influência dos valores de uma pessoa na atividade de consumo de joias? Quais são os significados atribuídos às joias pelos consumidores? Quais são as características e influências marcantes no consumo desse tipo de artefato? Existem grupos distintos de consumidores no tocante ao consumo de joias?

Para tentar responder a essas questões, e ao mesmo tempo para fomentar novas reflexões sobre temas complexos e abrangentes como o que foi até aqui apresentado, surgiu a motivação em conduzir pesquisa com o objetivo principal de se entender quais são os aspectos mais importantes atrelados ao consumo de joias.

A pesquisa se justifica por alguns motivos. Do ponto de vista teórico, o estudo visa a preencher uma lacuna quanto à relação entre materialismo e outros construtos levando em consideração o consumo de joias, o qual é praticamente inexplorado tanto nos estudos de consumo como no campo do comportamento do consumidor.

Ligado ao consumo, não se pode deixar de enfatizar que o trabalho pode contribuir para demonstrar como e por que uma apreciação mais profunda das coisas - no caso, joias pode levar a um entendimento mais profundo das pessoas (MILLER, 2013), noção que parece ser central para o campo da cultura material.

Já no que tange às questões mercadológicas práticas, esse "silêncio" em relação ao consumo de joias parece intrigante, pois, no mercado de luxo, os produtos gerados pela indústria de gemas e de joias cada vez mais se aproxima da realidade dos consumidores. Isso porque, segundo o Serviço Brasileiro de Apoio às Micro e Pequenas Empresas (SEBRAE) (SEBRAE, 2012), a busca do luxo está na fuga da banalidade, e o que se quer é algo extraordinário, que fuja ao comum. Esse novo luxo é construído no setor de gemas e de joias com a mistura de pedras e de metais preciosos com materiais alternativos como madeira, couro e sementes.

Além disso, cabe comentar que, historicamente, as marcas luxuosas de joias eram reservadas para poucos privilegiados, os ricos e a elite. Hoje em dia, muitos dos produtos dessa indústria não são mais restritos para as classes ricas e, portanto, as abordagens de segmentação com base em critérios como renda parecem ser insuficientes. Mesmo que os consumidores mais jovens e menos abastados sejam mais propensos a pagar por apenas um ou dois itens selecionados de sua marca de luxo favorita, eles estão dispostos a economizar dinheiro para essa compra, e a orgulhosamente apresentá-la ao seu grupo de referência.

O artigo está estruturado da seguinte forma: inicialmente, foi elaborada seção visando a sucintamente revisar alguns pontos importantes sobre o materialismo, bem como a apresentar alguns pontos atinentes ao consumo de joias. A seção posterior privilegiou o percurso metodológico adotado no estudo. Em seguida, os principais resultados do trabalho foram apresentados e discutidos à luz da literatura. Por fim, a última seção destacou as reflexões finais. 


\section{FUNDAMENTAÇÃO TEÓRICA}

\subsection{Refletindo sobre a Cultura Material: A relação entre as pessoas e os objetos}

Iniciado nos anos de 1980 e continuado após, é possível perceber movimento no campo dos estudos relacionados à pesquisa do consumidor no sentido de se aprofundar na relação entre as pessoas e os objetos - para citar apenas alguns, Csikentmihalyi e RochbergHalton (1981), Cummings e Lewandowska (2000), Brown (2003), Gregson (2007), Appadurai (2008) e Miller (2008).

Nesses estudos, busca-se entender melhor a relação entre as pessoas e seus pertences. No caso, parte-se do pressuposto de que a melhor maneira de entender, de transmitir e de apreciar a humanidade seria dar maior foco à materialidade (BELK, 2012; MILLER, 2013), uma vez que os bens representam formas sociais e partilhas de conhecimento muito complexas (APPADURAI, 2008).

O tema central da cultura do consumo é a maneira pela qual ela articula, à forma de organização da sociedade, as questões no tocante ao modo como se deve ou se quer viver. Ou seja, está ligada a valores, a práticas e a instituições fundamentais que definem a modernidade ocidental, como a opção, o individualismo e as relações de mercado (SLATER, 2002).

Dessa forma, a leitura sobre o consumo e sobre outras questões correlatas - no caso, o materialismo - deve se dar por meio da busca de significados que são criados e transferidos, uma vez que os bens de consumo têm significância que vai além de seu caráter utilitário e de seu valor comercial (McCRACKEN, 2003). E, dessa visão cultural, simbolicamente derivam todas as utilidades (SAHLINS, 2005).

Na medida em que "utilidade" é o conceito de "necessidade" apropriado a uma ordem cultural, ele deve incluir uma representação, por meio das propriedades concretas do objeto, assim como das relações entre pessoas. Isto é, "o 'sistema de necessidades' deve ser sempre relativo, não avaliável como tal pela necessidade e, em consequência, simbólica por definição" (SAHLINS, 2005, p. 151). No caso dos bens, eles representam um código-objeto para a significação e a avaliação de pessoas, bem como ocasiões, funções e situações vivenciadas por elas (SAHLINS. 2005).

Os bens de consumo são um importante meio da sociedade, visto que a eles são atribuídos diversos significados públicos e privados. Eles auxiliam nas escolhas, ao mesmo tempo em que ajudam a tornar a cultura concreta e pública. Além disso, não deveriam direcionar para o egoísmo, para a vaidade e para a ganância, uma vez que conquistam justamente porque conseguem capturar os significados com os quais as vidas são construídas (McCRACKEN, 2012).

Douglas e Isherwood (2006) ratificam essa noção, ao afirmarem que o consumo é algo ativo e constante na vida diária e nela desempenha papel central como estruturador de valores que constroem identidades, que regulam relações sociais, que definem mapas culturais, e assim por diante. Nesse sentido, os bens são investidos de valores criados socialmente tanto para expressar categorias e princípios quanto para cultivar ideias, para fixar 
e sustentar estilos de vida, ou para enfrentar mudanças. Complementarmente, Belk (1988) assume a ideia de que os consumidores consideram seus pertences como parte deles, com os objetos constituindo uma extensão do self de cada pessoa.

Nesse contexto em que os bens passam a assumir papel importante nas relações construídas na sociedade de consumo e essencial para se entenderem diversas questões ligadas ao mundo contemporâneo, fica mais fácil perceber por que o materialismo passou a ser amplamente pesquisado no campo do consumo. Essa forte ligação entre materialismo e consumo pode ser atribuída basicamente a três questões fundamentais: os indivíduos materialistas elevam os bens materiais a algo central em suas vidas; os indivíduos materialistas consideram a quantidade de bens materiais como forma de mensurar o sucesso individual; e, por fim, eles acreditam que existe uma forte relação entre felicidade e novas aquisições e posses de produtos (RICHINS; DAWSON, 1992).

Os consumidores materialistas, independente de sua classe social ou de seu poder aquisitivo, valorizam a posse e o poder da aquisição, e os consideram um importante meio que permeia suas atitudes, seus julgamentos e suas comparações entre objetos específicos. Essa posse é feita em termos de valores pessoais, de modo que os bens que uma pessoa considera importantes refletirão nesses valores (RICHINS; DAWSON, 1992; RICHINS, 1994; BURROUGHS; RINDFLEISCH, 2002; WONG, 1997). Pessoas que possuem esse comportamento são consideradas materialistas, pois priorizam a aquisição de bens materiais, enquanto os indivíduos que não sentem essa necessidade são considerados não materialistas (BELK, 1985; RICHINS; DAWSON, 1992).

Face a essa discussão, parece ganhar vulto a relação entre as pessoas e um artefato que tende a reunir diversas características a ponto de torná-lo um interessante foco de análise: as joias.

A joia é percebida em oposição a objetos que têm uma funcionalidade, como acessórios ou roupas. Isso se transforma em vantagem, pois a joia, em vez de "servir para alguma coisa" é associada ao prazer, ao sonho, à fantasia. Além disso, a joia nunca é vista como um objeto qualquer: ela é situada sempre na esfera do especial. Por "estar ligada a momentos especiais na relação com o outro, ao afeto e ao sentimento, a joia está num nível superior" (IBGM, 2004, p. 11).

Ou seja, parece plausível e coerente lançar mão do consumo de joias para ter acesso a importantes considerações acerca do materialismo. Nesse contexto, começa a fazer sentido tentar entender o consumo de joias e suas relações com outras temáticas, tema da próxima seção.

\subsection{Consumo de Joias e o Modelo Teórico da Pesquisa}

Algumas das noções envolvendo as joias levam à constatação de que, muito mais do que por sua função utilitária - "aquilo que são" - elas são valorizadas, procuradas e desejadas por características mais subjetivas e intangíveis, sejam elas estimuladas por valores individuais ou culturais - "aquilo que representam" (SCARABOTO et al, 2006). 
É justamente a partir dessa noção que, ao se buscar investigar o consumo de joias, parecem fazer sentido os trabalhos de Scaraboto, Zilles e Rodriguez (2005) e de Scaraboto et al. (2006), enfocados em determinar os valores dos consumidores e os significados inerentes ao consumo de luxo, bem como alguns fatores influenciadores do consumo de luxo.

Com relação ao construto valor, os valores atribuídos aos objetos representam não só o valor do objeto em si, mas também o que esse significa para o sentimento de alguém. Para que haja valor, é necessário que o sujeito reconheça determinada qualidade de um objeto, e tal reconhecimento é possível pela satisfação de uma necessidade do indivíduo. Então valor é tudo aquilo que for apropriado para satisfazer determinadas necessidades humanas, inclusive as espirituais (Hessen, 2001).

Wiedmann, Hennings e Siebels (2007) propuseram modelo de valores relativos aos produtos de luxo, dentre os quais se situam as joias, composto por quatro dimensões: valor financeiro, valor funcional, valor individual e valor social.

Enquanto a dimensão financeira aborda aspectos monetários e preços como sinais para exclusividade e singularidade, a dimensão funcional se refere a benefícios básicos do produto, tais como qualidade superior e excelente performance. $O$ valor individual representa orientação pessoal de um cliente para o consumo de luxo, com aspectos de autoidentidade, bem como motivos de compra materialistas e hedonistas. Por fim, a dimensão social da percepção de valor de luxo se concentra na orientação do prestígio, do consumo de status e de consumo conspícuo (Wiedmann; HENNINGS; SIEBELS, 2007; Veblen, 1998). E, considerando que os motivos para a compra de bens de luxo tornaram-se altamente diferenciados, não há comprador de luxo típico, mas vários grupos de consumidores (Hennigs et al., 2013).

Contemplando as temáticas já discutidas, foi proposto modelo teórico para a pesquisa, com apresentação gráfica da relação (entre o materialismo e o conjunto de joias por meio da inserção do construto materialismo como um importante antecedente de três construtos: valor, significado e características. A partir de Scaraboto et al. (2006), três dimensões foram assumidas como valor: valor pessoal, qualidade e sofisticação (ver Figura 1).

No que tange aos significados do consumo de joias proposto no modelo, é possível afirmar que significados são percepções ou interpretações individuais de algo, essencialmente subjetivas, simbólicas e psicológicas. Essas percepções ou interpretações tendem a se combinar para permitir, às pessoas, categorizar experiências e atribuir-lhes sentido (KLEINE III; KERNAN, 1991; 1998). Para o presente estudo, julgou-se pertinente considerar, tal como proposto por Scaraboto et al. (2006), as dimensões hedonismo, adequação e distinção.

Por fim, o construto características foi incluído levando-se em conta que o consumo de joias é permeado por questões ligadas às tendências da moda, aos meios familiar e profissional, à imagem das marcas e das grifes, aos anúncios de revistas e da mídia em geral, e ao consumo desse bem por celebridades (SCARABOTO et al., 2006). 


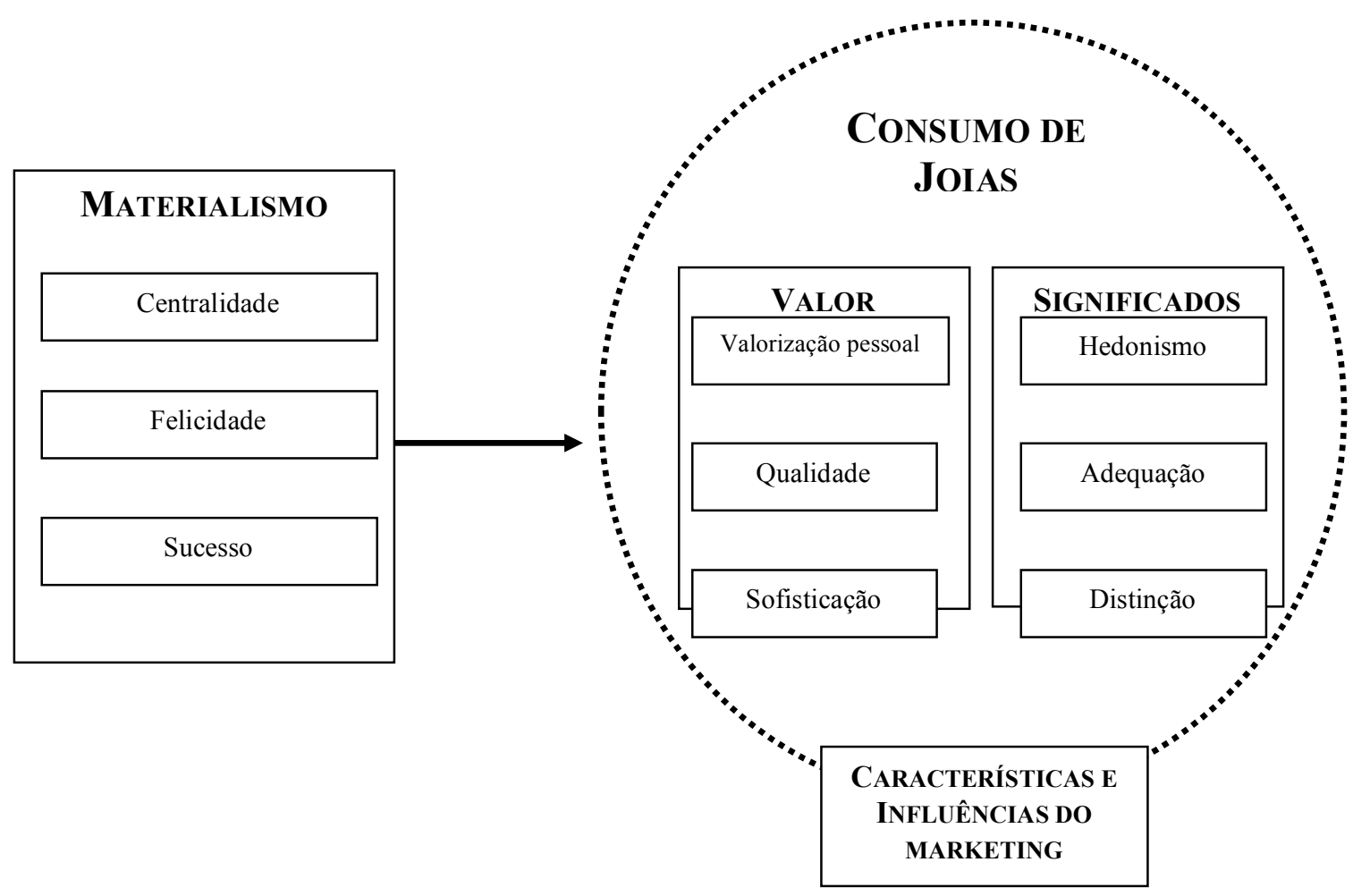

FIGURA 1 - Modelo teórico

Fonte: Elaboração própria

Apresentado o modelo teórico adotado, já é possível descrever o percurso metodológico da pesquisa empírica para, em seguida, apresentar e discutir os principais resultados.

\section{PERCURSO METODOLÓGICO DA PESQUISA EMPÍRICA}

A presente pesquisa pode ser definida como descritiva, uma vez que tem, como objetivo principal, a descrição e o relato de como ocorrem certos fenômenos ou de como se comportam certas variáveis em determinada situação (MALHOTRA, 2001). Como desenho mais apropriado, optou-se pelo survey interseccional, visto que o escopo constituiu-se em uma descrição de tempo único e na determinação de relações entre variáveis (BABBIE, 1999).

O instrumento foi composto 57 questões fechadas, distribuídas da seguinte forma:

a) trinta e sete questões relacionadas aos construtos valores, significados, características e influências do Marketing, conforme Scaraboto et al. (2006); 
b) quatro questões atinentes ao grau de influências no consumo de joias; e

c) dezesseis questões referentes ao construto materialismo, de acordo com a adaptação da escala de materialismo de Richers (2004) realizada por Torres, Pereira e Santos (2012).

Além dessas questões, foram incluídas perguntas relacionadas ao perfil do entrevistado: gênero, idade, estado civil, renda e escolaridade.

Os itens referentes aos construtos foram mensurados com escala do tipo Likert de cinco pontos ( 1 - discordo totalmente, até 5 - concordo totalmente). As questões de perfil e de influência utilizaram escalas nominais e ordinais.

Com o intuito de esclarecer aos respondentes o que seria considerado joia para fins do estudo, o instrumento apresentou uma breve definição: "Entende-se como joia todo objeto que é destinado para adorno pessoal, confeccionado com ligas de metais preciosos (ouro e prata) e ou com pedras (naturais ou sintéticas). Nessa categoria também estão incluídas as peças elaboradas em material não precioso, revestidas por metal nobre como ouro e prata, tendo, como característica, a aparência de joia, classificadas como folheados".

A fim de atender aos propósitos da pesquisa e respeitar o recorte estabelecido do perfil da amostra - usuários e consumidores de joias - incluiu-se um pergunta-filtro: "Você possui joia?". Se a resposta fosse negativa, o respondente era direcionado para o encerramento do questionário.

As questões foram disponibilizadas em uma plataforma online de acesso livre. Antes da disponibilização na internet, foi realizado pré-teste do instrumento para amostra de 10 usuários de joias, cujas respostas foram descartadas para fins de análise dos resultados.

O instrumento de coleta de dados foi enviado para endereços de e-mail obtidos a partir da rede de relacionamento dos pesquisadores e compartilhado nas redes sociais Linkedln e Facebook, resultando em amostra não probabilística, por conveniência. A coleta de dados pela internet é meio de alta flexibilidade, que permite abordar grande diversidade de questões, que favorece o anonimato do entrevistado - facilitando a obtenção de respostas delicadas - e que permite coleta de dados rápida com baixo custo (MALHOTRA, 2001), características aderentes ao objeto de pesquisa.

Foram obtidas 263 respostas, durante o período de 31 de julho a 17 de setembro de 2013 , oriundas de 216 respondentes que assinalaram "sim" à pergunta-filtro e que puderam prosseguir no preenchimento do questionário.

$\mathrm{Na}$ fase de análise dos dados, foram utilizadas quatro técnicas estatísticas: teste t e análises de correlação, de regressão múltipla e de cluster. A análise de regressão múltipla, técnica estatística utilizada para analisar a relação entre uma variável dependente e várias variáveis independentes, usa as variáveis independentes para prever os valores da variável dependente selecionada pelo pesquisador (Hair et al , 2005).

A análise de cluster ou de conglomerados, por sua vez, estuda todo o conjunto de relações interdependentes e examina relações de interdependência entre a totalidade do conjunto de variáveis. Seu objetivo é classificar objetos em grupos relativamente 
homogêneos, com base no conjunto de variáveis considerado (MALHOTRA, 2001) - ou seja, no caso da pesquisa em questão, identificar perfis de usuários de joias relativamente homogêneos. Cabe ressaltar que se buscou testar a análise de cluster em duas situações, com dois e três grupos, tendo-se chegado à conclusão de que a divisão em dois grupos seria a mais adequada por apresentar dados mais fidedignos.

Foi utilizado o software SPSS versão 16.0 para analisar os dados. Evidencia-se o nível de significância adotado $(\alpha=0,05)$ e o intervalo de confiança (95\%).

\section{APRESENTAÇÃO E DISCUSSÃO DOS RESULTADOS}

\section{Caracterização dos respondentes}

Cerca de $85 \%$ da amostra foi composta de mulheres. Quanto à idade, quase $75 \%$ dos respondentes declarou ter até 40 anos, sendo a faixa de 26 a 30 anos a que se apresentou como a mais representativa. No tocante ao grau de escolaridade, $28,2 \%$ dos entrevistados indicou ter curso superior completo e $31,0 \%$ informou ter cursado uma especialização. A maioria dos entrevistados (quase 58\%) declarou ter renda familiar entre dois e cinco salários mínimos.

Outro dado importante tem a ver com a frequência do uso de joias: $43,5 \%$ dos entrevistados afirmou utilizar esse bem ocasionalmente, enquanto $35,6 \%$ sinalizaram usar sempre. Por fim, quase $45 \%$ dos entrevistados informou comprar e, às vezes, ser presenteado com joias.

\section{Confiabilidade das escalas}

Para a análise da confiabilidade das escalas foi utilizado o alfa de Cronbach. O cálculo da confiabilidade foi realizado separadamente para cada um dos construtos (MALHOTRA, 2001). Os valores do alfa de Cronbach para as escalas utilizadas são indicados na Tabela 1.

Tabela 1 - Confiabilidade das escalas

\begin{tabular}{c|c|c}
\hline ConSTRUTO & DimensõES & ALPHACRONBACH \\
\hline \multirow{3}{*}{ Valor } & Valorização pessoal & 0,876 \\
\cline { 2 - 3 } & Qualidade & 0,830 \\
\cline { 2 - 3 } & Sofisticação & 0,805 \\
\hline \multirow{3}{*}{ Significados } & Hedonismo & 0,831 \\
\cline { 2 - 3 } & Adequação & 0,631 \\
\cline { 2 - 3 } $\begin{array}{c}\text { Características e } \\
\text { Influências do } \\
\text { marketing }\end{array}$ & Distinção & 0,752 \\
\hline \multirow{2}{*}{ Materialismo } & - & 0,786 \\
\cline { 2 - 3 } & & \\
\cline { 2 - 3 } & & 0,880 \\
\hline
\end{tabular}

Fonte: Elaboração própria 
Pode-se observar que a maioria das dimensões dos construtos analisados teve confiabilidade satisfatória, levando em consideração, conforme apontado por Hair et al (2005), os valores de 0,60 a 0,70 como limite inferior de confiabilidade. A exceção fica por conta da dimensão felicidade do construto materialismo, que apresentou índice um pouco abaixo de 0,60. Esse resultado é coincidente com o relato da pesquisa envolvendo o construto materialismo de Torres, Pereira e Santos (2012), onde se verificou também valor do alfa ligeiramente abaixo de 0,60.

\section{Análise de correlação e regressão múltipla}

A fim de responder às indagações emergentes enunciadas na introdução do presente trabalho, conduziu-se a análise do coeficiente de correlação de Pearson entre os construtos e outras variáveis de interesse (ver Tabela 2). Os resultados parecem indicar que existe correlação significa, positiva e moderada entre o construto materialismo e os construtos valor, significados, e características e influência.

\section{Tabela 2 - Coeficientes de Correlação de Pearson}

\begin{tabular}{c|c}
\hline CONSTRUTO/VARIÁVEL & MATERIALISMO \\
\hline Valor & 0,372 \\
\hline Significados & 0,482 \\
\hline Características e Influência & 0,235 \\
\hline
\end{tabular}

Nota: ${ }^{*} p<0,01$

Fonte: Elaboração própria

A partir da análise de correlação, que forneceu "pistas" de que os construtos estavam correlacionados, decidiu-se seguir adiante na tarefa de análise dos dados por meio do método de regressão linear (HAIR et al, 2005; MALHOTRA, 2001). Assim, três modelos de regressão foram ajustados:

Modelo 1: $[$ Valor $]=\beta_{0}+\beta_{1}[$ Materialismo $]+\beta_{2}[$ Influência do marketing $]+e$

Modelo 2: $[$ Significados $]=\beta_{0}+\beta_{1}[$ Materialismo $]+\beta_{2}[$ Influência do marketing $]+e$

Modelo 3: $[$ Características $]=\beta_{0}+\beta_{1}[$ Materialismo $]+\beta_{2}[$ Influência do marketing $]+e$

Por meio dos resultados apresentados na Tabela 3, pode-se destacar que o Modelo 1 de regressão ajustado explica aproximadamente $18 \%$ da variação do valor atribuído às joias, levando em conta o materialismo e a influência do Marketing. Essa variação alcança $29 \%$ no caso do construto significados, e apenas $9 \%$ no Modelo 3, onde o construto características é variável dependente. Ainda que esses níveis sejam considerados baixos, os resultados parecem levar a algumas discussões interessantes.

Primeiramente, no caso do Modelo 1, cabe considerar que uma das dimensões do construto valor é valorização pessoal, que leva em conta que as joias são valorizadas pela 
capacidade de proporcionar benefícios emocionais e psicológicos, assim como prazer, sentimentos e sensações positivas. Já a qualidade tem a ver com a inclinação que os consumidores teriam a valorizar as joias que aparentassem ter sido produzidas com tecnologia e matéria-prima superiores. Por fim, a sofisticação considera a propriedade das joias como algo que aprimora o visual das pessoas, tornando-as mais sofisticadas.

Para o Modelo 2, no qual a variável dependente é o construto significados, também valem algumas considerações. O hedonismo parece ter aderência ao consumo de joias, visto que elas são consideradas como parte do self dos consumidores pelo fato de envolverem sentimentos, fantasia e imaginação. A adequação está relacionada às pessoas manterem certo padrão de marcas e de estilo em seu vestuário e em sua aparência, com o intuito de sempre parecerem bem vestidos e apresentados. A distinção, por fim, considera que as joias têm o poder de melhorar a imagem de quem as consome, uma vez que refletem o conhecimento e o nível cultural, bem como o status dos indivíduos (SCARABOTO et. al, 2006).

Tabela 3 - Resultados dos modelos de regressão ajustados

\begin{tabular}{|c|c|c|c|c|c|c|}
\hline Modelo & $\begin{array}{c}\text { Variável } \\
\text { Dependente }\end{array}$ & $\begin{array}{c}\text { Variável } \\
\text { Independente }\end{array}$ & B & e. p. & $\begin{array}{c}\text { Sig. } \\
\text { (Coeficientes) }\end{array}$ & $\mathbf{R}^{2}$ \\
\hline \multirow[b]{2}{*}{ Modelo 1} & \multirow[b]{2}{*}{ Valor } & Materialismo & 0,490 & 0,101 & 0,000 & \multirow[b]{2}{*}{0,178} \\
\hline & & $\begin{array}{c}\text { Influência do } \\
\text { marketing }\end{array}$ & $-0,190$ & 0,059 & 0,001 & \\
\hline \multirow[b]{2}{*}{ Modelo 2} & \multirow[b]{2}{*}{ Significados } & Materialismo & 0,443 & 0,064 & 0,000 & \multirow[b]{2}{*}{0,291} \\
\hline & & $\begin{array}{c}\text { Influência do } \\
\text { marketing }\end{array}$ & 0,157 & 0,038 & 0,000 & \\
\hline \multirow[b]{2}{*}{ Modelo 3} & \multirow[b]{2}{*}{ Características } & Materialismo & 0,198 & 0,076 & 0,001 & \multirow[b]{2}{*}{0,097} \\
\hline & & $\begin{array}{l}\text { Influência do } \\
\text { marketing }\end{array}$ & 0,138 & 0,044 & 0,002 & \\
\hline
\end{tabular}

Fonte: Elaboração própria

Por fim, o Modelo 3 sinaliza que o materialismo influencia as características do consumo de joias. Isso quer dizer que o comportamento em relação ao consumo de joias parece ser moldado pelo convívio com familiares, com parentes e com colegas. Além disso, vale mencionar que os consumidores sofrem influências da imagem das marcas e das grifes, dos anúncios de revistas e da mídia em geral, assim como de hábitos das celebridades.

Todos esses resultados parecem ter articulação com a ideia do materialismo, uma vez que o indivíduo materialista valoriza a posse e o poder da aquisição, e os considera importante meio para justificar suas atitudes, julgamentos e comparações entre objetos específicos. Nesse sentido, o materialismo tende a contemplar a ideia de que as pessoas mais materialistas julgam o seu sucesso e o dos outros pela posse que os indivíduos acumulam: ser bem-sucedido está relacionado ao acúmulo de bens que ajudam a projetar as imagens desejadas. Além disso, 
essas pessoas tendem a colocar suas posses e aquisições como ponto central em suas vidas (RICHINS; DAWSON, 1992).

Esse, portanto, é um importante achado do presente trabalho, pois foi constatada a existência de relação entre materialismo e os construtos analisados no tocante ao consumo de joias.

Essa discussão envolvendo os resultados entre materialismo e os construtos valor, significados e características só vem a reforçar o que é defendido pelos autores da cultura material. Sintetizados por Douglas e Isherwood (2006), eles enfatizam que é por meio dos significados públicos vinculados aos bens e aos seus usos públicos que o consumo organiza a ordem social, trazendo à tona divisões, categorias e classificações sociais, entre outros. Isto é, são essas classificações que determinam os significados das coisas, e que refletem a própria ordem social. Em outras palavras, os significados e rituais de consumo demarcam as categorias e as classificações que constituem a ordem social.

\section{Delineamento dos grupos de consumidores}

Levando em consideração as questões envolvendo os construtos materialismo, valor, significados e características, os resultados da análise de cluster permitem afirmar que existem dois grupos distintos de consumidores de joias, com $52,3 \%$ do total da amostra tendo sido enquadrados no Grupo 1, enquanto 47,7\% foram classificados como Grupo 2 (ver Tabela 4).

Tabela 4 - Distribuição dos respondentes nos agrupamentos

\begin{tabular}{c|c|c}
\hline Grupos & $\begin{array}{c}\text { Frequência } \\
\text { Absoluta }\end{array}$ & $\begin{array}{c}\text { Percentual } \\
\text { (\%) }\end{array}$ \\
\hline Grupo 1 & 113 & 52,3 \\
\hline Grupo 2 & 103 & 47,7 \\
\hline TOTAL & $\mathbf{2 1 6}$ & $\mathbf{1 0 0 , 0 0}$ \\
\hline
\end{tabular}

Fonte: Elaboração própria

A partir daí, foram calculadas as médias dos construtos materialismo, valor, significados e características. Percebe-se que os consumidores do Grupo 1 tenderam a concordar total ou parcialmente com boa parte das afirmações envolvendo os construtos pesquisados. Por sua vez, os consumidores do Grupo 2 assumiram posição de discordância com relação às afirmações feitas (ver Tabela 5). 
Tabela 5 - Caracterização dos dois perfis dos respondentes

\begin{tabular}{c|c|c}
\hline Grupos & Grupo 1 & Grupo 2 \\
\hline Caracterização & Os vistosos & Os discretos \\
\hline $\begin{array}{c}\text { Média do construto } \\
\text { Materialismo* }\end{array}$ & 2,38 & 1,61 \\
\hline Média do construto Valor* & 3,82 & 2,12 \\
\hline $\begin{array}{c}\text { Média do construto } \\
\text { Significados* }\end{array}$ & 2,80 & 1,63 \\
\hline $\begin{array}{c}\text { Média do construto } \\
\text { Características e Influências* }\end{array}$ & 2,02 & 1,23 \\
\hline
\end{tabular}

Nota: * Escala de 1 a 5

Fonte: Elaboração própria

Buscou-se, também, caracterizar os dois grupos de consumidores. O Grupo 1, nomeado de "Os Vistosos", pode ser entendido como o conjunto de consumidores que apresentam maior grau de materialismo quando comparados com o Grupo 2. Ou seja, tendem a valorizar o sucesso, a centralidade e a felicidade proporcionada pelos bens materiais - no caso da presente pesquisa, as joias. No mesmo sentido, os consumidores classificados no Grupo 1 também apresentaram tendência a atribuir notas mais altas para os construtos valor, significados e características e influências das joias.

Por sua vez, o Grupo 2 (chamado de "Os Discretos") pode ser caracterizado por consumidores que tendem a atribuir menor nota ao seu comportamento materialista, além de perceber as joias com pouco valor, e com pouco significado relacionado ao hedonismo, à adequação e à distinção.

\section{CONSIDERAÇÕES FINAIS}

Face a todos os resultados, algumas constatações parecem emergir, principalmente quando confrontados com alguns autores apresentados na revisão da literatura.

Em primeiro lugar, é importante refutar o consumo como algo ruim, supérfluo, destruidor das relações e do meio ambiente. A ideia defendida no presente trabalho vem se juntar a autores da cultura material que advogam a favor do consumo dos bens como algo importante e inerente à natureza humana. Ainda que Csikentmihalyi e Rochberg-Halton (1981) tenham proposto uma classificação entre "bom materialismo" e "materialismo ruim" a partir do objetivo de consumir - entendendo consumo como forma de atualização pessoal e desenvolvimento de laços com familiares e amigos versus consumo com intenção de gerar inveja e ostentação - pode-se advogar que o materialismo não deve ser entendido como o lado negro do consumo, ou como algo pernicioso que deve ser combatido. Muito menos deve 
ser aceito que as pessoas que possuem mais bens têm de ser mais materialistas do que as que não os possuem (MILLER, 2002).

Em segundo lugar, pode-se enfatizar que o foco do presente trabalho foi a investigação de um bem ainda pouco explorado na literatura de consumo, cujas características o tornam adequado ao entendimento de questões ligadas ao consumo e à cultura material.

Dessa forma, o consumo de joias, uma vez que é permeado por valor, por significados e por influências, parece auxiliar os indivíduos a fazerem escolhas, e a ajudá-los a tornar sua cultura - entendida como a teia de significados construída social e culturalmente na interação entre os grupos - como algo concreto e público (McCRACKEN, 2012).

Ou seja, tal como enfatizado por Miller (2013), o consumo de joias pode contribuir para se alcançar entendimento, ainda que parcial, das pessoas. A demanda por esses bens surge como função de um conjunto de práticas e de classificações sociais em vez de uma revelação das necessidades humanas (APPADURAI, 2008). Em outras palavras, o que está em jogo é a noção de que os objetos constroem os sujeitos, e isso serve para a compreensão cotidiana do significado de sermos humanos (MILLER, 2013).

Outra questão é a ideia de que o materialismo ou o consumo de bens drena a humanidade. Isso pode conduzir a uma visão simplista e falsa de uma humanidade pura e imaculada, que não leva em conta que as mais sofisticadas relações com as coisas podem ser encontradas entre diversos povos antes mesmo das revoluções industrial e comercial, cujas posses materiais parecem desprezíveis quando comparadas com a dos indivíduos da sociedade de consumo atual (BELK, 1988).

Além disso, as joias, ao serem entendidas como selfs dos indivíduos, podem dizer muito sobre quem eles são. As pessoas muitas vezes exibem seus bens como um sinal de identidades desejadas para os outros e, não raramente, para si (BELK, 1988).

Retornando às indagações que motivaram a condução da presente investigação, podese dizer que existe relação entre alguns atributos importantes do consumo de joias e o materialismo, atributos esses representados pelos construtos valores, significados e características e influências.

Além disso, foi possível constatar que os consumidores de joias não podem ser considerados como um grupo homogêneo, obediente e fiel a padrões fixos, mas sim como indivíduos que constroem seus valores e seus significados, e que sofrem influências de maneiras diferentes. Dessa forma, o modelo teórico proposto para a presente pesquisa parece fazer sentido, pois foi constatado que o consumo de joias é permeado por questões como valorização, qualidade, sofisticação, hedonismo, distinção, entre outras.

Sendo assim, a partir das discussões empreendidas, é possível trazer à tona algumas implicações para os campos de estudo relacionados. Em primeiro lugar, conforme enfatizado pelos autores consultados - em especial, McCracken (2012) e Douglas e Isherwood (2006) - os consumidores lançam mão dos bens para dizer alguma coisa sobre si mesmos, para reafirmar suas identidades, para definir sua posição no espaço social, para declarar seu pertencimento 
a um ou outro grupo, para falar de gênero e etnia, para celebrar ou superar passagens, para afirmar ou negar suas relações com os outros, ou para atribuir quaisquer outros significados.

Dessa maneira, parece ser mais plausível passar a considerar o materialismo como algo que serve para situar o indivíduo enquanto tal e como pertencente ao grupo do qual faz parte ou almeja participar, e não como uma característica negativa ou condenável. O trabalho também parece trazer à baila algumas questões que são centrais para o campo do macromarketing, principalmente quando foca suas atenções nas discussões acerca do materialismo, da cultura material, do consumismo, da influência do marketing sobre os indivíduos, entre outros pontos.

Em segundo lugar, para o campo da pesquisa do consumidor, mais precisamente para o consumo de joias, os resultados parecem remeter à constatação de que esse consumidor apresenta uma construção de significados diferenciada, fruto de uma vivência construída cotidianamente não somente com essa importante categoria de bens, mas também articulada em um grande círculo de interação social: com os integrantes da família, com amigos, com colegas, com vizinhos, com comunicações midiáticas e com outros atores.

O referencial teórico acerca da cultura material, ainda pouco explorado nas pesquisas do consumo no Brasil, parece indicar profícuas "trilhas" de investigação para futuras pesquisas. Cabe destacar ainda que os resultados do presente estudo podem constituir caminho revelador para os gestores de empresas ofertantes de produtos e de serviços relacionados ao mercado de joias e correlatos.

Nesse ponto, torna-se pertinente discutir algumas limitações da pesquisa. A principal delas está relacionada à decisão de implementação online do questionário, iniciativa que pode ter enviesado o perfil dos entrevistados.

A outra limitação, muitas vezes inevitável nesse tipo de estudo, é atinente ao chamado viés de desejabilidade social (CROWNE e MARLOWE, 1960). Tal viés é resultante de respostas atribuídas pelo respondente que não são baseadas naquilo que ele realmente acredita ou pratica, mas no que percebe sendo socialmente apropriado responder ou naquilo que é projetado como ideal. Levando-se em conta o público pesquisado, essa questão não pode passar despercebida.

Além disso, cabe salientar o fato de que a escala de materialismo utilizada, embora devidamente adaptada para o contexto brasileiro, foi desenvolvida em contexto com traços culturais distintos da população brasileira. Por fim, ainda é pertinente salientar que, devido à opção metodológica de coleta de dados por meio de um survey na internet, os valores e os significados foram levados em conta sem a interferência do contexto, o que pode ser considerado limitador para a discussão dos resultados.

É possível apontar, também, algumas sugestões para estudos posteriores e complementares que possam contribuir para uma base de conhecimento sobre os temas aqui tratados. Uma delas tem a ver com a inclusão de outros construtos tangentes à temática do consumo de joias - por exemplo, autoestima, influência da mídia e de celebridades no consumo, estilos de consumo, entre outros. Tal como pesquisado por Torres, Pereira e Santos 
(2012), seria interessante investigar em que medida o consumo de joias pode estar relacionado ao nível de felicidades material e experiencial. Nesse ponto, pode ser descortinada uma série de outras possibilidades de articulação entre o consumo de joias e a temática, também complexa, relacionada ao construto denominado bem-estar de consumir. Outra sugestão pode caminhar no sentido de ampliar a amostra para outros públicos e para outros estratos de renda.

\section{Referências}

APPADURAI, A. A vida social das coisas: As mercadorias sob uma perspectiva cultural. Niterói: EdUFF, 2008.

BABBIE, E. Métodos de Pesquisa de Survey. Belo Horizonte: Editora UFMG, 1999.

BARBOSA, L. Apresentação. IN: BARBOSA, L.; CAMPBELL, C. (org). Cultura, Consumo e Identidade. Rio de Janeiro: Editora FGV, 2006.

BARBOSA, L.; CAMPBELL, C. O Estudo do Consumo nas Ciências Sociais Contemporâneas. IN: BARBOSA, L. ; CAMPBELL, C. (org). Cultura, Consumo e Identidade. Rio de Janeiro: Editora FGV, 2006.

BELK, R. W. Three Scales to Measure Constructs Related to Materialism: Reliability, validity, and relationship to measure of happiness. Advances in Consumer Research, v. 11, n. 1, p. 291-297, 1984.

BELK, R. W. Materialism: trait aspects of living in the material world. Journal Consumer Research, $v$. 12, p. 265-280, 1985.

BELK, R. W. Possessions and the extended self. Journal of Consumer Research, v. 15, 1988.

BELK, R. W. People and things. In: WELLS, V.; FOXALL, G. (org.) Handbook of Developments in Consumer Research. Nothampton: Edward Elgar Publishing, 2012.

BROWN, B. The sense of things: the object matter of American literature. Chicago: University of Chicago, 2003.

BURDSAL, C. J. An Examination of Second Order Motivational Factors as Found in Adults. Journal of Genetic Psychology, v. 127, p. 83-89, 1975.

BURROUGHS, J. E.; RINDFLEISCH, A. Materialism and Well-Being: A conflicting values perspectives. Journal of Consumer Research, v. 29, n. 3, p. 348-370, 2002.

CROWNE, D. P.; MARLOWE, D. A new scale of social desirability independent of psychopathology. Journal of Consulting Psychology, 24, p. 349-354, 1960.

CSIKENTMIHALYI, M.; ROCHBERG-HALTON, E. The meaning of things: domestic symbols and the self. Cambridge: Cambridge University Press, 1981.

CUMMINGS, N.; LEWANDOWSKA, M. The value of things. London: Publiskers for Architecture, 2000.

DESJEUX, D. O Consumo: Abordagens em Ciências Sociais. Maceió-AL: EDUFAL, 2011.

DOUGLAS, M.; ISHERWOOD, B. O Mundo dos Bens: Para uma antropologia do consumo. Rio de Janeiro: Editora UFRJ, 2006.

BOURDIEU, Pierre. A Distinção: crítica social do julgamento. São Paulo: Edusp; Porto Alegre: Zouk, 2007.

GER, G.; BELK, R. W. Cross-cultural Differences in Materialism. Journal of Economic Psychology, v. 17, n. 1, p. 55-77, 1996. GREGSON, N. Living with things: ridding, accommodation, dwelling. London: Sean Kingston Publishing, 2007. 
GRIFFIN, M.; BABIN, B. J.; CHRISTENSEN, F. A cross-cultural investigation of the materialism construct. Journal of Business Research, v. 57, n. 8, p. 893-900, 2004.

HAIR, J. F.; ANDERSON, R. E.; TATHAM, R. L.; BLACK, W. C. Análise multivariada de dados. 5ạ edição. Porto Alegre: Bookman, 2005.

HENNIGS, N., WIEDMANN, K. P., KLARMANN, C.; BEHRENS, S. The concept of luxury: a global phenomenon with local implications. The European Financial Review, 2013, p. 62-4.

HESSEN, J. A filosofia dos valores. Coimbra - Portugal: Almedina, 2001.

IBGM - Instituto Brasileiro de Gemas e Metais Preciosos. A joia, o jovem e o luxo emocional. Brasília, 2004.

JUSTICE, B.; BIRKMAN, R. An effort to distinguish the violent from the nonviolent. Southern Medical Journal, v. 65, p. 703-706, 1976.

KLEINE III, R. E.; KERNAN, J. B. Contextual influences on the meanings ascribed to ordinary consumption objects. Journal of Consumer Research, v. 18, p. 311-24, 1991.

KLEINE III, R. E.; KERNAN, J. B. Measuring the meaning of consumption objects: an empirical investigation. Advances in Consumer Research, v. 15, p. 498-504, 1988.

MCCRACKEN, G. Cultura e consumo: novas abordagens ao caráter simbólico dos bens e das atividades de consumo. Rio de Janeiro: Mauad, 2003.

MCCRACKEN, G. Cultura e Consumo II: mercados, significados e gerenciamento de marcas. Rio de Janeiro: Mauad, 2012.

MALHOTRA, N.. Pesquisa de Marketing. Porto Alegre: Bookman, 2001.

MILLER, D. Teoria das Compras: o que orienta as escolhas dos consumidores. São Paulo: Nobel, 2002.

MILLER, D. Consumo Como Cultura Material. Horizontes Antropológicos, ano 13, n. 28, p. 33-63, jul./dez. 2007.

MILLER, D. The comfort of things. Cambridge: Polity Press, 2008.

MILLER, D. Trecos, Troços e Coisas: estudos antropológicos sobre a cultura material. Rio de Janeiro: Jorge Zahar, 2013.

RICHINS, M. L.; DAWSON, S. A consumer values orientation for materialism and its measurement: scale development and validation. Journal Consumer Research, 19, p. 303-316, 1992.

RICHINS, M. L. Special possessions and the expression of material values. Journal Consumer Research, 21, p. 522-533, 1994.

ROCHA, E. Cenas do Consumo: Notas, ideias, reflexões. Revista Semear, n. 06. Rio de Janeiro: PUC-Rio, 2002.

SAHLINS, M. D. Cultura e Razão Prática. Rio de Janeiro: Jorge Zahar, 2003.

SCARABOTO, D., ZILLES, F. P., RODRIGUEZ, J. B., KNY, M. A. Pequenos luxos, prandes prazeres significados do consumo e valores dos consumidores de joalheria e vestuário de luxo. In: EnANPAD, 30‥ Anais... Salvador-BA: ANPAD, 2006.

SCARABOTO, D.; ZILLES, F. P.; RODRIGUEZ, J. B. Relacionando Conceitos sob a Perspectiva Cultural do Consumo: Podemos comparar consumo de luxo e materialismo? In: EnANPAD, 29‥ Anais... BrasíliaDF: ANPAD, 2005.

SEBRAE - Serviço Brasileiro de Apoio às Micro e Pequenas Empresas. (n.d.). Lapidando a imagem da joia brasileira. Recuperado de http://201.2.114.147/bds/bds.nsf/AA0CDFB4C6BDF0B083257279004756C2/\$File/NT00035016.pdf.

SLATER, D. Cultura do Consumo e Modernidade. São Paulo: Nobel, 2002.

TORRES, P. de A., PEREIRA, R. de C. de F., SANTOS, J. P. Em busca da felicidade: uma pesquisa sobre o bem-estar no consumo. In: EnANPAD, 36‥ Anais... Rio de Janeiro: ANPAD, 2012. 
VEBLEN, T. A teoria da classe ociosa: um estudo econômico das instituições. São Paulo: Nova Cultura, 1988.

WATSON, J. J. The relationship of materialism to spending tendencies, saving, and debt. Journal of Economic Psychology, v. 24, n. 6, p. 723-739, 2003.

WIEDMANN, K. HENNINGS, N., SIEBELS, A. Mensuring consumers` luxury value perception: a crosscultural framework. Academy of Marketing Science Review. V. 7, 2007.

WONG, N.Y.C. Suppose you own the world and no one knows? Conspicuous Consumption, Materialism and Self. Advances in Consumer Research, v. 24, p. 197-203, 1997. 